\title{
This Is Not an Autonomous Sensory Meridian Response Video During COVID
}

\author{
Lealani Mae Y. Acosta, M.D. \\ Department of Neurology, Vanderbilt University Medical Center, A-1088 Medical Center North, Nashville, TN, USA.
}

J Gen Intern Med 37(4):970

DOI: $10.1007 / \mathrm{s} 11606-021-07264-9$

(c) Society of General Internal Medicine 2021

${ }^{66} \mathrm{~A}$ utonomous sensory meridian response (ASMR) is a of particular audio-visual stimuli triggers intense, pleasurable tingling sensations in the head and neck regions, which may spread to the periphery of the body ${ }^{1}$ "

Rustled paper unfolds, crinkling like an glass vial underfoot.

A soft palm flattens curves of cotton sheets, smooths lotion into her chapped, still hands.

Dextrose whispers escape; salinated eye drops suspend and splash.

A red plastic comb tames an unforgiving raven bouffant.

A metallic bite clips with a satisfying snap through fingernails.

Machines whir and drone in monotone,

Pumps heave and sigh in bloated bursts.

The ventilator's whooshes

pulse with sinuous waves.

Regularly irregular beeps everywhere.

Flashing numbers ticking up and down,

up and down, moving target?

Pressures: blood, cerebral, ulcers, positive end expiratory.

The steady drip of an IV

spring rain water torture

pianissimo staccato on a tin roof

Received August 3, 2021

Accepted October 29, 2021

Published online January 11, 2022
Beads of condensation coalesce from labored breathing, gathering on ridged endotracheal tubes

translucent face shields, opaque with fog

A blue-gloved hand holds hers in comfort, easing

the pain of a turn for the worse.

Sterile encouragement.

Echoes once absorbed by family and friends at bedside ricochet into

the germ-free, visitor-free, careful, care-filled COVID unit

The sights and sounds of the intensive unction

administered in hopes of salvation

in isolation

during COVID19.

Corresponding Author: Lealani Mae Y. Acosta, M.D.; Department of Neurology, Vanderbilt University Medical Center, A-1088 Medical Center North, Nashville, TN 37212, USA (e-mail: lealani.mae. acosta@vumc.org).

\section{Declarations:}

Conflict of Interest: The author declares that she does not have a conflict of interest.

\section{REFERENCES}

1. Fredborg B, Clark J, Smith SD. An Examination of Personality Traits Associated with Autonomous Sensory Meridian Response (ASMR). Front Psychol. 2017;8:247. Published 2017 Feb 23. https://doi.org/10.3389/ fpsyg.2017.00247.

Publisher's Note Springer Nature remains neutral with regard to jurisdictional claims in published maps and institutional affiliations. 